\title{
Penentuan Permintaan dan Nilai Tambah Produk Industri Kreatif Pada Pasar Lokal
}

\author{
Made Irma Dwiputranti ${ }^{1}$, Andriyani Oktora ${ }^{2}$, Dodi Permadi ${ }^{3}$
}

\begin{abstract}
Recently, creative industries growth significantly. However, this growth is still constrained by various factors, one of which is the funding. This aspect has not been solved well although there has full government support. This is due among other things: 1) there is no form of financing schemes in accordance with the creative industries; 2) the amount of commitments lending by financial institutions is not adequate. 3) have not been socialized and performing well. This constraint requires more detailed analysis of the aspects most and very influential on the growth of the creative industries. This research was conducted through analysis of the logical framework approach as well as industrial cluster approach to the object in the fashion and design, which is well established in Bandung. Outcomes were include: 1) identification of critical success factors (CSF) in small industry based on the demand and the potential of the locality; 2) the mapping capitalization model of stimulus and treatment of the CSF; 3) analysis of products value-added based on demand and market; 4) analysis of capital policy for the creative industry.
\end{abstract}

Keywords. critical success factor, creative industry, policy, funding.

\begin{abstract}
Abstrak. Industri kreatif menunjukan pertumbuhan yang signifikan. Namun, pertumbuhan ini masih terkendala dengan berbagai faktor, salah satunya adalah permodalan. Aspek ini belum terpecahkan dengan baik walaupun sudah ada dukungan penuh pemerintah. Hal ini disebabkan antara lain: 1) belum ada bentuk skema pembiayaan yang sesuai; 2) jumlah komitmen penyaluran pinjaman lembaga keuangan belum memadai; 3) belum tersosialisasi dan terlaksana dengan baik. Kendala ini membutuhkan analisis lebih rinci tentang aspek yang paling dan sangat berpengaruh terhadap pertumbuhan industri kreatif. Penelitian ini dilakukan melalui analisis logical framework approach serta pendekatan cluster industri dengan objek pada fesyen dan desain yang merupakan industri kreatif cukup mapan di Kota Bandung. Luaran yang didapatkan antara lain: 1) identifikasi critical success factors (CSF) pada industri kecil berbasiskan demand dan potensi lokalitas; 2) terpetakannya model stimulus pemodalan dan treatment CSF; 3) analisis nilai tambah produk berbasiskan permintaan dan pasar; 4) analisis kebijakan permodalan bagi industri kreatif.
\end{abstract}

Kata kunci. critical success factor, industri kreatif, kebijakan, permodalan.

\section{Pendahuluan}

Saat ini nilai investasi industri kreatif dalam negeri diproyeksikan tidak kurang dari Rp 150

\footnotetext{
${ }^{1}$ Made Irma Dwiputranti, Jurusan Teknik Industri, Politeknik Pos Indonesia, Jl. Sariasih No. 54, Bandung. (email: irma_dwiputranti@yahoo.com).

${ }^{2}$ Andriyani Oktora, Jurusan Teknik Industri, Politeknik Pos Indonesia, Jl. Sariasih No. 54, Bandung. (email: aoktora1@gmail.com).

${ }^{3}$ Dodi Permadi, Jurusan Teknik Industri, Politeknik Pos Indonesia, J1. Sariasih No. 54, Bandung. (email: permadi311@yahoo.com)
}

Diajukan: 17-11-2015

Diperbaiki: 20-04-2016 triliun atau sekitar 8\% dari PDB, (21 Januari 2010, Business News). Nilai yang cukup signifikan bagi industri kreatif. Hal ini didukung oleh KADIN Bidang Koperasi dan UKM yang memproyeksikan industri kreatif Indonesia mampu bertumbuh hingga 35\%. Hal ini sangat mendukung perkiraan pertumbuhan Indonesia sebesar 3.2\% (Deperindag, 2010). Indikator ini bisa terlihat dari perkembangan yang sangat dominan pada beberapa industri berbasis kreativitas. Melalui kajian-kajian (Bapedda Kota Bandung, Deperindag Propinsi Jawa Barat dan Kota Bandung) terdapat 4 besar industri kreatif yang telah cukup mapan antara lain desain, fesyen (distribution outlet), musik, dan kuliner. Industri ini berkembang karena multiplyer effect dari salah satu industri. Industri kreatif musik adalah salah satu pemicu multiplyer tersebut. 
Diawali oleh banyaknya musik indie yang berkembang kemudian membentuk komunitas, kemudian merepresentasikan komunitasnya mulai desain (gambar) khusus yang berbeda dengan yang lain. Desain ini kemudian ditampilkan dalam media kaos, kemeja, jaket dan aksesoris lain yang menampilkan perbedaan antar komunitas tersebut (Jatmiko, 2009).

Saat ini, industri kreatif membutuhkan dukungan pemerintah berupa fasilitasi pengadaan infrastruktur yang baik, kemudahan perizinan, dan peniadaan pungutan liar (Riyanto, 2001). Industri kreatif membutuhkan kebebasan dalam menciptakan sesuatu. Namun, pelaku usaha ekonomi kreatif seringkali terkendala biaya dalam mengembangkan usaha dan produktivitas. Melalui Inpres No.6/2009 (BN No. 7853 hal. IB -
ISB) tentang pengembangan industri kreatif, pemerintah telah meminta seluruh kementerian dan lembaga terkait serta pemerintah daerah untuk melakukan rencana aksi pengembangan usaha ekonomi kreatif. Usaha tersebut antara lain: (1) kegiatan ekonomi berbasis kreativitas, keterampilan, dan bakat individu yang bernilai ekonomis; (2) pemerintah akan meminta pihak perbankan untuk mendukung pengembangan usaha ekonomi kreatif dengan memberikan pinjaman modal.

Hasil studi Kementerian Perdagangan (dalam Rencana Pengembangan Ekonomi Kreatif 2009 2015), pengembangan industri kreatif menghadapi sejumlah kelemahan dari aspek pembiayaan. Pertama, belum ada bentuk skema pembiayaan yang sesuai dengan industri kreatif

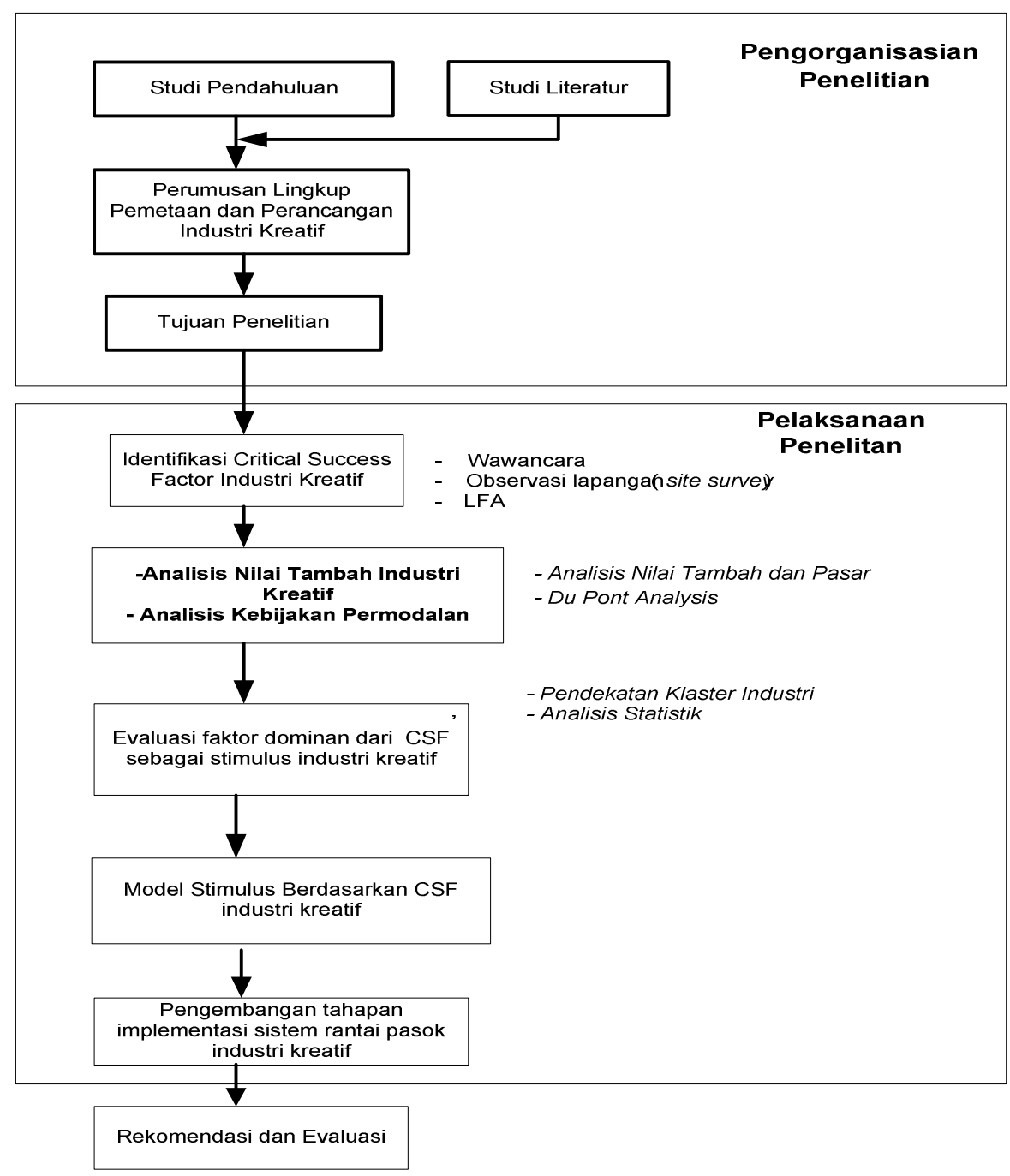

Gambar 1. Metodologi penelitian 
dimana syarat kolateral pada skema kredit konvensional memberatkan, dan tidak memotivasi pelaku industri kreatif karena seluruh risiko harus ditanggungnya. Kedua, jumlah komitmen penyaluran pinjaman oleh lembaga keuangan belum memadai kebutuhan usaha industri ini. Ketiga, belum tersosialisasi dan terlaksana dengan baik seluruh aspek kelemahan di atas akan menjadi hambatan untuk perkembangan industri kreatif, terutama dalam upaya mendukung pertumbuhan ekonomi secara umum. Dibutuhkan peran pemerintah dalam bentuk dukungan yang lebih meringankan jika upaya pemodalan perbankan butuh perbaikan secara organisasi yang lebih rigid. Hal ini mengingat industri kreatif sangat fleksibel dan tumbuh berkembang alami (Leon, 1969).

Kajian aspek kebijakan pemodalan melalui pengembangan modal dapat dikaji melalui perbaikan infrastuktur, dukungan IT (teknologi) dan fasilitas (insentif) yang lebih menarik.

\section{Metodologi}

Pada penelitian ini metode pelaksanaannya dilakukan melalui penelitian pendahuluan dengan observasi lapangan (wawancara, penyebaran kuesioner, workshop, dan brainstroming), dilanjutkan dengan desk study sebagai langkah proses analisis mendalam dengan workshop terbatas dengan para stakeholder. Gambar 1 menggambarkan metode pelaksanaan penelitian yang dilakukan selengkapnya.

\section{HASIL DAN PEMBAHASAN}

Dalam penelitian ini dilakukan proses survei, brainstorming, dan diskusi melalui responden. Jumlah respondennya adalah 31 perusahaan. Gambar 2 menyajikan sejumlah stakeholder sentra industri fesyen Kota Bandung beserta pemetaan kedudukan mereka dalam sistem klaster industri tersebut.

Sebagian stakeholder sebagaimana disebutkan
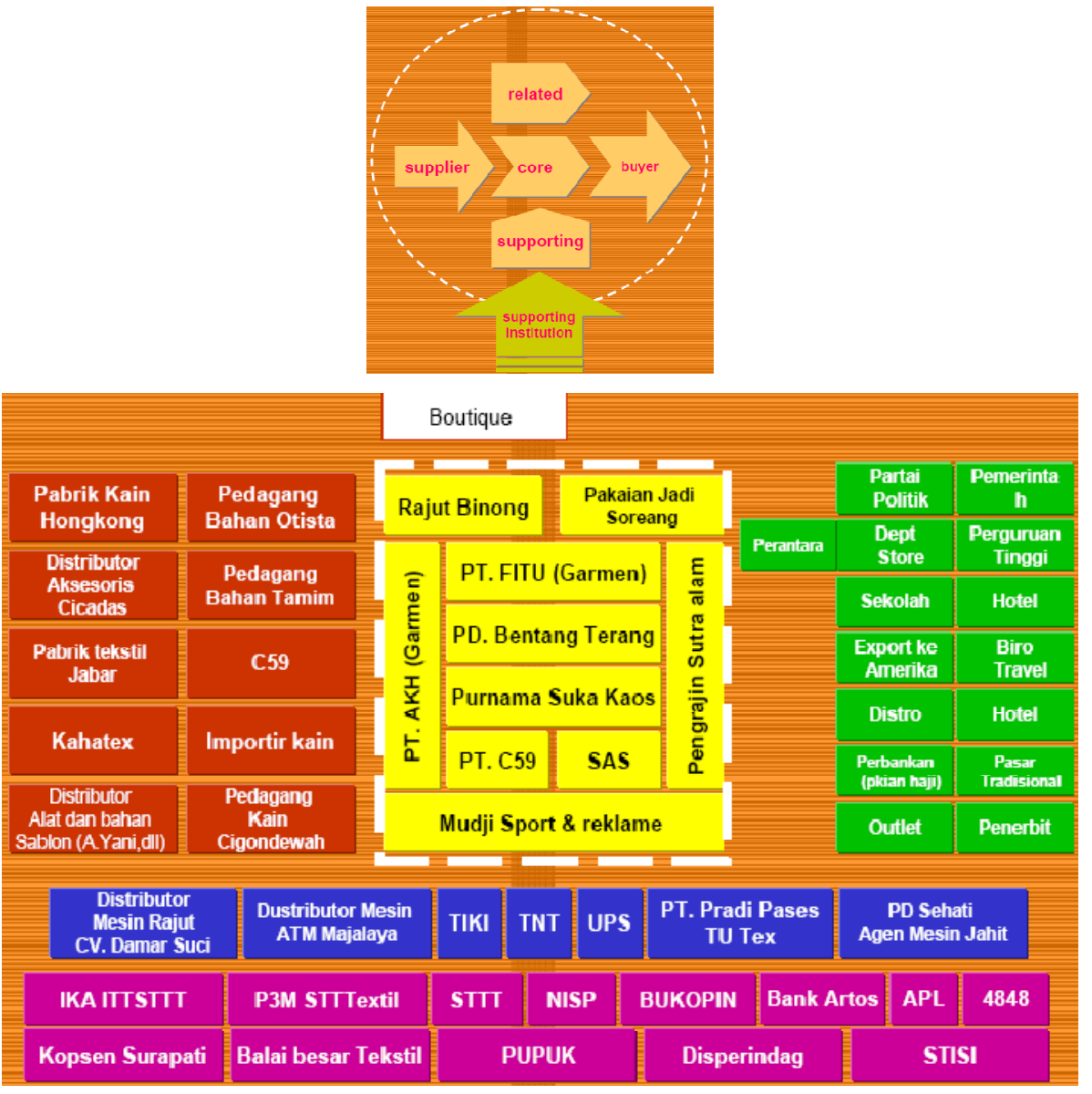

Gambar 2. Struktur klaster industri fashion Kota Bandung 
di atas baik dari kalangan pelaku usaha, industri pendukung dan terkait, serta pihak-pihak berkepentingan lainnya perlu diundang dalam suatu pertemuan focus group discussion (FGD) yang diselenggarakan atas inisiatif penelitian ini.

\section{Analisis Masalah dan Potensi Industri Fesyen}

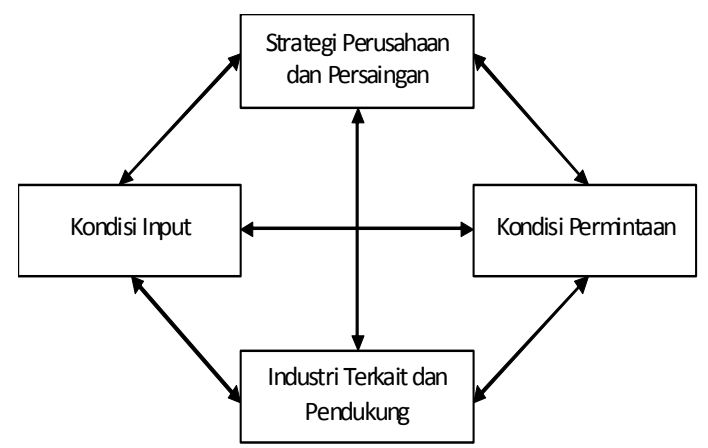

Gambar 3. Diagram analisis kondisi klaster fashion
Masalah keunggulan daya saing sentra industri fesyen dapat diidentifikasi dengan menggunakan model diamond competitiveness Porter. Berdasarkan model tersebut faktor-faktor yang dikaji berkaitan dengan keunggulan daya saing sentra industri fesyen yaitu kondisi input, kondisi permintaan, kondisi strategi perusahaan dan persaingan, serta kondisi industri terkait dan pendukung. Selain faktor penghambat (masalah) dalam pembahasan ini juga disajikan faktorfaktor pendukung (potensi) keunggulan daya saing sentra industri fesyen Kota Bandung (Porter, 1998).

Quality control (QC) secara umum dilakukan secara terpisah dan memiliki pola yang berbeda antar setiap konveksi atau penjahit. Pada dasarnya pengecekan kualitas dilakukan pada pra produksi, produksi dan pasca produksi. Secara umum industri kreatif yang ada di Kota Bandung telah melakukannya walaupun dilakukan secara tidak seragam.

Tabel 1. Analisis kondisi input klaster industri fashion

\begin{tabular}{ll}
\hline Pendukung & Penghambat \\
\hline - Sentra industri tekstil & - Sinergi pembinaan belum terwujud \\
Jabar & - Majalaya menjadi kota yang semrawut \\
- Lokasi strategis & - Mesin modern belum dimiliki \\
- Dilalui beberapa jurusan & - Daerah banjir \\
angkot & - Bahan baku mengandalkan impor dengan harga mahal \\
- Bandung sebagai kota & - Keamanan (demonstrasi, bom, gempa bumi) \\
fashion dan trend & - Bank tidak percaya ITPT \\
- SDM tekstil relatif & - Sulit perijinan \\
tersedia & - Biaya transportasi mahal \\
- Banyak sekolah terkait & - Biaya dan pajak promosi mahal \\
- Ada fasilitasi promosi & - Biaya energi (listrik dan BBM) naik terus \\
dan misi dagang dari & - Program pemerintah kurang menyentuh terhadap pengusaha \\
pemerintah & kecil tentang pemberdayaan ekonomi pengusaha kecil dan \\
- Bahan baku tersedia & menengah \\
& - Proses perijinan kurang transparan \\
& - SDM kurang trampil \\
& - SDM turn over tinggi \\
& - Peran pemerintah sebagai mediator antara perguruan tinggi \\
& dan pengusaha dalam mengembangkan desain tidak \\
& maksimal \\
& - Vendor banyak tapi sedikit yang kualitasnya konsisten \\
& - Riset dan pengenbangan untuk UKM masih sangat kurang \\
& - Pilihan bahan baku terbatas (kurang variatif) \\
& - dalam jumlah kecil) \\
\hline & \\
& \\
&
\end{tabular}


Tabel 2. Analisis strategi perusahaan dan persaingan klaster industri fashion

\begin{tabular}{ll}
\hline Pendukung & Penghambat \\
\hline- Tersedia industri yang & - Budaya jiplak masih tinggi \\
terintegrasi di & - Kurang kesadaran untuk bekerja sama antar perusahaan untuk \\
Indonesia & memenuhi permintaan pasar \\
& - Permodalan yang terbatas \\
& - Job order menghasilkan margin kecil \\
& - Desain tidak berkembang jika hanya mengandalkan job order \\
& - Kompetitor banting harga \\
& - Komunikasi dan kerja sama usaha dengan industri pendukung \\
& belum terbina dengan baik \\
& - Kesadaran desain masih rendah \\
& - Belum menerapkan bakuan kompetensi SDM \\
& Tidak tersedia informasi yang cukup yang menggambarkan \\
& - Pekhususan tentang jenis produk \\
- & Sulit membuat proyeksi prospek waktu pelanggan akan pesan kaos \\
\hline
\end{tabular}

Tabel 3. Analisis kondisi permintaan klaster industri fashion

\begin{tabular}{ll}
\hline Pendukung & Penghambat \\
\hline - Adanya permintaan yang signifikan dari luar negeri & - Standart produk kaos belum optimal \\
$\quad$ untuk produk tekstil yang berbahan baku serat alam & - Tingginya permintaan dengan merk \\
- Job order (pasar pasti) & asing \\
- Permintaan lokal tinggi & - Kurang sosialisasi standart mutu \\
- Belanja pemerintah untuk TPT meningkat & ITPT \\
- Peningkatan angkatan sekolah & - Isyu lingkungan hidup (limbah \\
- Permintaan ekspor cukup tinggi & sablon) \\
- Potensi kebutuhan sandang sangat tinggi (220 juta & - Sarana dan prasarana tidak \\
$\quad$ orang penduduk Indonesia) & mendukung \\
- Kualitas produk cukup bersaing & \\
\hline
\end{tabular}

Tabel 4. Analisis kondisi industri terkait dan pendukung klaster industri fashion

\begin{tabular}{ll}
\hline Pendukung & Penghambat \\
\hline- Banyak terdapat perguruan tinggi dengan jurusan & - Suplai bahan baku tidak konsisten \\
& desain \\
- Industri bahan pembantu cukup & \\
- Industri aksesories cukup & \\
\hline
\end{tabular}

Quality control dilakukan oleh pemilik desain atau pemesan dengan pemilik yang menetapkan standar kualitas dan standar kualitas yang diinginkannya (customer). apabila tidak memenuhi standar maka akan dikembalikan ke supplier. Produk jadi akan dicek dengan pengecekan fisik yang mengacu pada standar kualitas yang diminta.

Pada penelitian ini dilakukan tahap pemetaan proses ini untuk menjelaskan detail setiap proses hal-hal yang menjadi faktor penentu karakteristik kualitas melalui pemaparan alur proses awal (input) sampai dengan proses akhir (output), spesifikasi yang dibutuhkan dari setiap proses dan standarisasi metode inspeksi kualitas (Simonim, 1997). Pemetaan proses secara keseluruhan dan khusus proses ini dapat disimpulkan seperti pada Gambar 4.

Pada Gambar 4 dapat dilihat bahwa terdapat 6-7 proses utama yang dilalui material/bahan baku. Pada penelitian yang diamati pada proses jahit, desain dan Sablon. karena dinilai bahwa proses tersebut memberikan kontribusi yang lebih besar terhadap penentuan perbaikan kinerja 
Tabel 5. Quality Control

\begin{tabular}{clcccl}
\hline \multirow{2}{*}{ No } & Objek Pengecekan & \multicolumn{3}{c}{ Pengecekan Kualitas } & Keterangan \\
\cline { 3 - 5 } & & $\begin{array}{c}\text { Pra- } \\
\text { Proses }\end{array}$ & $\begin{array}{c}\text { Proses } \\
\text { Produksi }\end{array}$ & $\begin{array}{c}\text { Pasca- } \\
\text { Proses }\end{array}$ & \\
\hline 1 & Desain & & & & I: Dilakukan \\
& Desain Awal (Ide/gagasan) & I & II & I & II: Kadang kadang \\
& $\quad$ Desain Gambar & I & II & I & III: Tidak Dilakukan \\
& $\quad$ Desain Prototife/Model & & & I & \\
2 & Bahan & I & & I & \\
3 & Material Pendukung & I & & I & \\
4 & Produksi & & & & \\
& Jahit & I & I & I & \\
& Sablon & I & I & I & \\
& Bordir & I & I & I & \\
& Printing & I & I & I & \\
\hline
\end{tabular}

Proses Produksi Kemeja

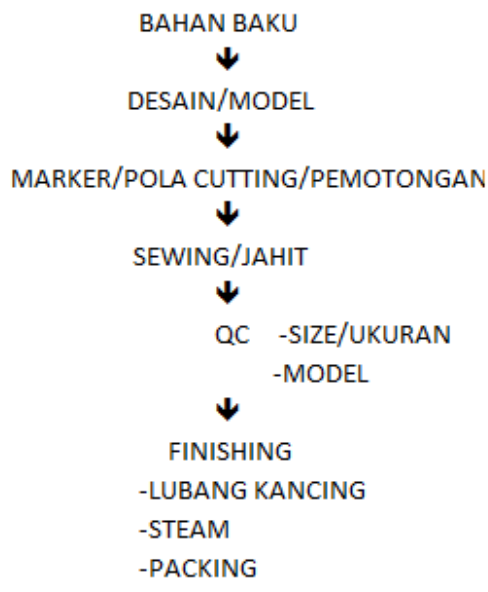

Proses Produksi Kaos

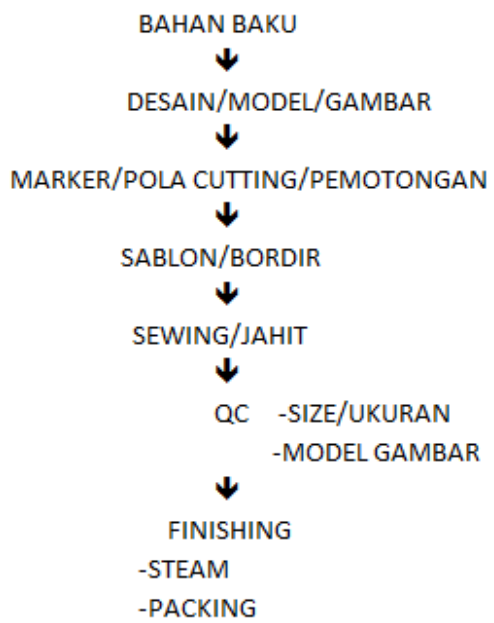

Gambar 4. Proses Produksi Kemeja dan Kaos

\section{Persentase Fokus Produksi \\ Produk Fashion}

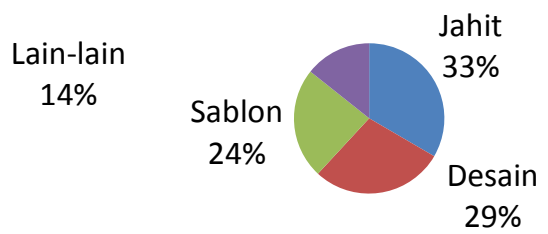

Gambar 5. Presentase Fokus Produksi

kualitas produk. Jika diamati perhatian besar untuk produk fesyen saat ini antara jahit dan desain memiliki bobot yang relatif hampir dekat walaupun masih lebih besar jahit. 
Tabel 6. Pengembangan Pengendalian Mutu Produk Fashion

\begin{tabular}{|c|c|c|}
\hline Proses & $\begin{array}{l}\text { Jenis } \\
\text { Pengendalian }\end{array}$ & Keterangan \\
\hline Pra- & Inspeksi dan & Inspeksi Kain dan Penyimpanannya \\
\hline Produksi & Pengujian & $\begin{array}{l}\text { Inspeksi kain, merupakan bagian yang sangat penting dan harus dilakukan } \\
\text { segera setelah kain diterima. Jika tidak sesuai agar dapat segera dilakukan } \\
\text { perbaikan oleh pabrik pembuatannya. Hal-hal yang perlu diinspeksi adalah: } \\
\text { lebar kain, sebab berkaitan dengan marker yang telah direncanakan, cacat- } \\
\text { cacat kain, baik cacat struktur anyaman atau cacat tenun, termasuk bowing } \\
\text { dan skewness, cacat celupan maupun cacat printing. } \\
\text { Penyimpanan kain sebelum diproses lebih lanjut, dimaksudkan agar tidak } \\
\text { kotor dan rusak, jika mungkin dalam suhu dan kelembaban relative tertentu } \\
\text { agar dimensi kain tidak berubah dan tidak ditumbuhi jamur. Ujung } \\
\text { gulungan diusahakan agar terlindungi dari sinar dan debu. } \\
\text { - Benang jahit } \\
\text { - Zipper } \\
\text { - Gelar susun kain (speardling) } \\
\text { - Pemotongan }\end{array}$ \\
\hline $\begin{array}{l}\text { Proses } \\
\text { Produksi }\end{array}$ & $\begin{array}{l}\text { Mutu Proses } \\
\text { Penjahitan }\end{array}$ & $\begin{array}{l}\text { Pada proses penjahitan sangat rentan terhadap terjadinya cacat, hal ini sangat } \\
\text { bergantung kepada tingkat keterampilan operator maupun kondisi } \\
\text { permesinan serta tingkat pengawasan dan inspeksi yang diterapkan. Cacat } \\
\text { pada proses penjahitan dapat terjadi pada hasil jahitan, sambungan jahitan } \\
\text { maupun pada penggabungan/perakitan. } \\
\text { Inspeksi dilakukan terhadap } \\
\text { - Cacat jahitan } \\
\text { - Cacat jahitan sambung } \\
\text { - Cacat pada perakitan } \\
\text { - Proses penyempurnaan }\end{array}$ \\
\hline $\begin{array}{l}\text { Pasca } \\
\text { Produksi }\end{array}$ & Inspeksi Akhir & $\begin{array}{l}\text { Pada pelaksanaan inspeksi akhir diperlukan adanya daftar pengamatan yang } \\
\text { menerangkan bagian mana dari pakaian yang harus diperiksa. Daftar } \\
\text { pengamatan yang harus ada tersebut adalah: } \\
\text { 1. Spesifikasi ukuran, menunjukkan dimensi dan toleransi bagian yang } \\
\text { harus diukur. } \\
\text { 2. Cara pengukuran, pada spesifikasi ukuran harus dicantumkan pula cara } \\
\text { pengukurannya. } \\
\text { 3. Spesifikasi mutu, yang meliputi mutu jahitan, mutu sambungan, mutu } \\
\text { perakitan, letak aksesoris, kancing, lubang kancing, saku, cuff, pelekatan } \\
\text { lapisan, penampilan hasil pressing/seterika, kenampakan pakaian, dll, } \\
\text { serta mutu kain jika ada yang terlewatkan pada inspeksi awal. }\end{array}$ \\
\hline
\end{tabular}

\section{Perancangan pengendalian produk fesyen}

Berdasarkan hasil pengolahan dan analisis, maka dapat dikembangkan rancangan pengendalian produk fesyen ini dengan acuan Tabel 6.

\section{SIMPULAN}

Berdasarkan pembahasan tersebut di atas, maka dapat dibuat kesimpulan:

1. Sistem kendali mutu proses produksi yang dihasilkan meliputi tahap pra produksi (inspeksi kain dan penyimpanannya, benang jahit, zipper, gelar - susun kain, dan cutting), tahap pengendalian mutu produksi (proses penjahitan, cacat jahitan, cacat sambungan kain, dan cacat perakitan), tahap pengendalian mutu proses penyempurnaan, dan tahap inspeksi akhir (dengan sistem penyaringan).

2. pasar berbasiskan standar mutu proses. Masalah nilai tambah dapat diidentifikasi melalui daya saing yang bisa digunakan melalui hasil produksi atau output, dengan menggunakan model diamond competitiveness Porter. Berdasarkan model tersebut faktorfaktor yang dikaji berkaitan dengan keunggulan daya saing sentra industri fesyen 
yaitu kondisi input, kondisi permintaan, kondisi strategi perusahaan dan persaingan, serta kondisi industri terkait dan pendukung. Faktor-faktor pendukung (potensi) keunggulan daya saing sentra industri fesyen Kota Bandung, antara lain: adanya permintaan yang signifikan sehingga mutu produk sangat berpengaruh terutama karena ada permintaan lokal tinggi, sehingga kualitas produk cukup bersaing.

\section{DAFTAR PUSTAKA}

Jatmiko, B. (2009). Pemetaan dan Perancangan Rantai Pasok Industri Kreatif Kota Bandung. Bandung: Poltekpos.

Porter, M.E. (1998). 'Clusters and the new economics of competition.' Harvard Business Review. Vol. 76 (6), pp $77-90$.

Rosenberg, L.J. (1969). Logical Framework Approch. USAID: Practical Concepts, Inc.

Riyanto, B. (2001). Dasar-dasar Pembelanjaan Perusahaan. Edisi Keempat. Yogyakarta: BPFE.

Simonin, B.L. (1997). 'The importance of collaborative know-how: An empirical test of the learning organization.' Academy of Management Journal, Vol. 40 (5), pp. $1150-1174$.

Stock, J.R.; Lambert, D.M. (2001). Strategic Logistics Management. 4th Edition. UK: Mc.Graw Hill. 